\title{
THE CIRCULAR DICHROISM OF PHOSPHOCHOLINE- SPECIFIC MOUSE HYBRIDOMA AND MYELOMA PROTEINS: UNUSUAL PROPERTIES OF THE HYBRIDOMA PROTEIN 101.6G6
}

\author{
N. Martin Young*, Ross E. Williams* and J. Latham Claflin $\dagger$ \\ *Division of Biological Sciences, National Research Council of Canada, 100 Sussex Drive, Ottawa, \\ Canada K1A 0R6; and †Department of Microbiology and Immunology, University of Michigan Medical \\ School, Ann Arbor, MI 48109, U.S.A.
}

(Received 23 July 1984; accepted 22 August 1984)

\begin{abstract}
The circular dichroism (CD) spectra of five myeloma and six hybridoma proteins specific for phosphocholine were measured in the $250-310-\mathrm{nm}$ range. The effect on the CD spectra of adding phosphocholine was also examined. The five myeloma proteins all had distinctive native spectra and, except for M603 and W3207, unique changes occurred on ligand binding. The hybridomas were chosen as pairs from each of the three known families of phosphocholine-specific immunoglobulins. Those from the T15 or M603 families resembled the appropriate prototype. However, the proteins from the M167 family were all distinctively different in their $\mathrm{CD}$ properties. In particular, the hybridoma protein $101.6 \mathrm{G} 6$ showed large $C D$ changes on hapten binding and values for the association constant for phosphocholine of $1.1 \times 10^{5} \mathrm{M}^{-1}$ and of $5.8 \times 10^{2} \mathrm{M}^{-1}$ for acetylcholine were obtained by $\mathrm{CD}$ spectrophotometric titration. The $\mathrm{CD}$ properties of the proteins are interpreted in the light of the sequence data so far available, including the possible role of the D-segment.
\end{abstract}

\section{INTRODUCTION}

The processes by which the repertoire of antibody variable regions is generated are now known in outline (Tonegawa, 1983). However variation in sequence may not automatically mean variation in function, i.e. specificity for antigen (Cohn et al., 1980; Kabat, 1981, 1982) and more detailed knowledge of the relationship of sequence to specificity is required. In particular, the role of the D-segment is not entirely clear. This gene segment and its junctions with the

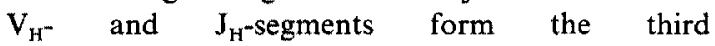
complementarity-determining region of the heavy chain (CDR3). The possibility exists that it may be a structural element rather than being directly involved in antigen binding (Potter, 1983).

Extensive sequence data [collected in Kabat et al. (1983)] and the X-ray crystallographic analysis of M603 Fab (Padlan et al., 1976) make the phosphocholine-specific immunoglobulins very suitable for studies of structure and function. The original group of mouse myeloma proteins were assigned on the basis of their hapten-binding properties to three families, typified by T15, M603 and M167 respectively (Leon and Young, 1971). Subsequently, various hybridoma proteins specific for phosphocholine were assigned to the same families on the basis of idiotypic analyses (Claflin et al., 1981), hapten profiles (Andres et al., 1981) and protein sequence analyses (Gearhart et al., 1981). The hapten-binding studies indicated that the proteins of the T15 family are relatively constant in their functional properties, as are those of the M603 family except for some variation in binding of an antigen from Proteus morganii. In contrast the proteins of the M167 family are quite diverse in their hapten-binding specificities. It may be possible to correlate the variations seen in the properties of proteins of the M167 family with differences in their amino-acid sequences.

Circular dichroism (CD) can provide additional information on both structural and functional aspects of antibodies. Earlier work on the phosphocholine-binding myeloma proteins (Morris et al., 1974) showed that the Fv regions contribute strongly to the near-u.v. CD. Spectra in this region, $250-310 \mathrm{~nm}$, arise chiefly from tyrosine and tryptophan chromophores. The structural differences among the three prototypic myeloma proteins gave rise to considerably different $C D$ spectra in this region. In addition, functional differences were evident since addition of the hapten phosphocholine caused different changes in the spectra of the three proteins. In this paper, we report further CD studies of phosphocholine-specific myeloma and hybridoma proteins, particularly the unique hybridoma protein, 101.6G6. This protein, though assigned to the M167 family (Claflin et al., 1981; Andres et al., 1981) has an H-chain derived from the VII member (Clarke et al., 1982) of the set of four T15 genes (Crews et al., 1981), while the other proteins are all derived from the VI gene. It also has a different D-segment (Clarke et al., 1983).

\section{MATERIALS AND METHODS}

Ascites fluids containing the M511, M603 and T15 proteins were given by Dr M. Potter, W3207 ascites fluid was given by Dr L. Hood and J558 ascites fluid 
by Dr B. Clevinger. The tumor lines MOPC 167 and MOPC 104E were propagated in this laboratory. The phosphocholine-specific proteins were purified using the affinity medium of Chesebro and Metzger (1972) or a medium prepared by reacting $p$-aminophenylphosphocholine with an $N$-hydroxysuccinimideactivated agarose gel [Affi-Gel 10 (Bio-Rad Laboratories Ltd, Mississauga, Ontario)]. Neither the ascites fluids nor the purified proteins were reduced, and the predominant oligomeric form was the dimer in all cases. M104E and J558 were purified on the dextran affinity medium of Hiramoto et al. (1972). M315 was purified from ascites fluid (Litton Bionetics Inc.) with a $\varepsilon$-dinitrophenyl-lysine Afti-Gel 10 column. The hybridoma proteins have been previously described (Claflin et al., 1981).

CD spectra were recorded on a Cary 61 instrument. The data are presented as mean residue molar ellipticities, $[\theta]_{\mathrm{mrw}}$, assuming a mean residue wt of 110. Protein concentrations were estimated using the extinction coefficient, $A_{280}^{\mathrm{lmg} m \mathrm{ml}}=1.35$, except for M 104E where 1.60 (Leon et al., 1970) was used. The samples were in $0.15 \mathrm{M} \mathrm{NaCl}, 0.01 \mathrm{M}$ phosphate buffer, $\mathrm{pH} 7.3$, except where noted.

\section{RESULTS}

\section{Phosphocholine-specific myeloma proteins}

In Fig. 1, the CD spectra of M511 and W3207 in the aromatic region are compared to the spectra of

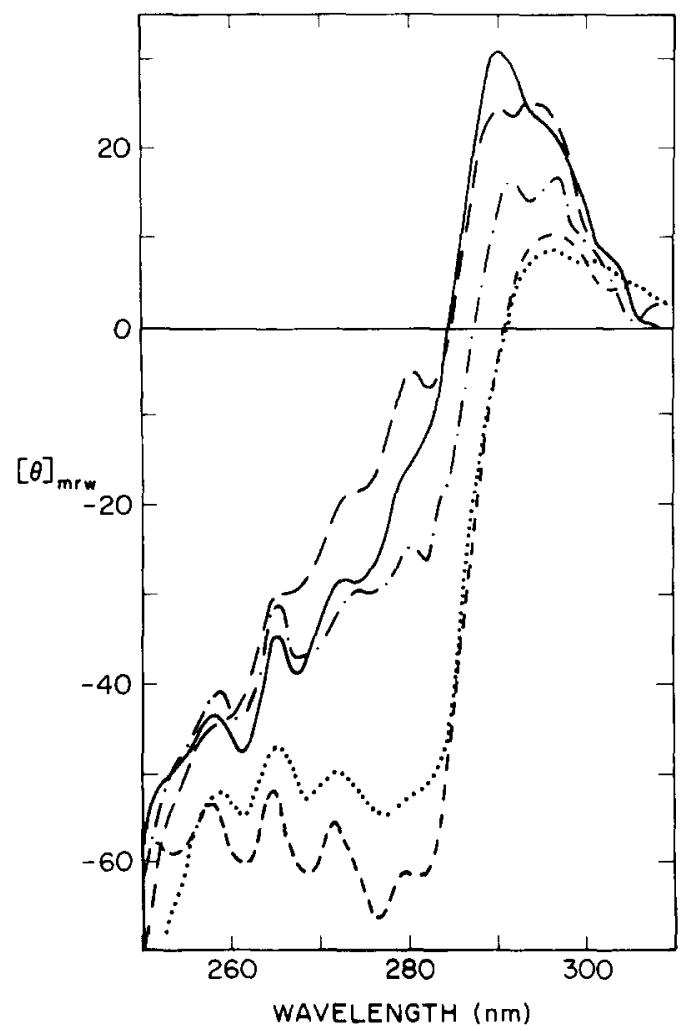

Fig. 1. CD spectra in the aromatic region of mouse myeloma proteins, all in the dimeric IgA form: T15 (--), W3207 (--), M603 (--), M511 (․) and M167 (---).
M603, T15 and M167, the prototypes for the three phosphocholine families. The spectra were recorded with non-reduced samples, predominantly in the dimeric IgA form, unlike those reported previously for M603, T15 and M167 (Morris et al., 1974). In the far-u.v. region, the $\mathrm{M} 511$ and $\mathrm{W} 3207$ proteins both had $[\theta]_{\mathrm{mrw}}$ values at $217 \mathrm{~nm}$ of -6700 degrees $\cdot \mathrm{cm}^{2} / \mathrm{dmole}$, greater than those of the other proteins which were between -4100 and -5600 degrees $\mathrm{cm}^{2} / \mathrm{dmole}$ (Morris et al. 1974). It is apparent that M511 resembles M167 in its CD spectrum, as might be anticipated from its idiotypy and overall sequence homology. W3207, though a member of the M603 family, has a $\mathrm{CD}$ spectrum more like that of T15. Clearly even the limited sequence differences within a family affect the structures of these proteins as reflected in the CD properties of their aromatic residues.

Addition of the ligand phosphocholine in sitesaturating amounts caused changes in the $C D$ spectra that were distinct for nearly all the proteins (Fig. 2). The exception is the W3207-M603 pair, which both showed similar positive shifts in ellipticity. The hapten profiles of M603 and W3207 are also similar. though their reactivities towards the $P$. morganii antigen are a little different (Andres et al., 1981). In the case of M 511, the spectral change produced by phosphocholine binding was greater than that of the other four proteins, particularly M167. Though related in many ways, M167 and M511 differ in hapten profile (Andres et al. 1981) and the association

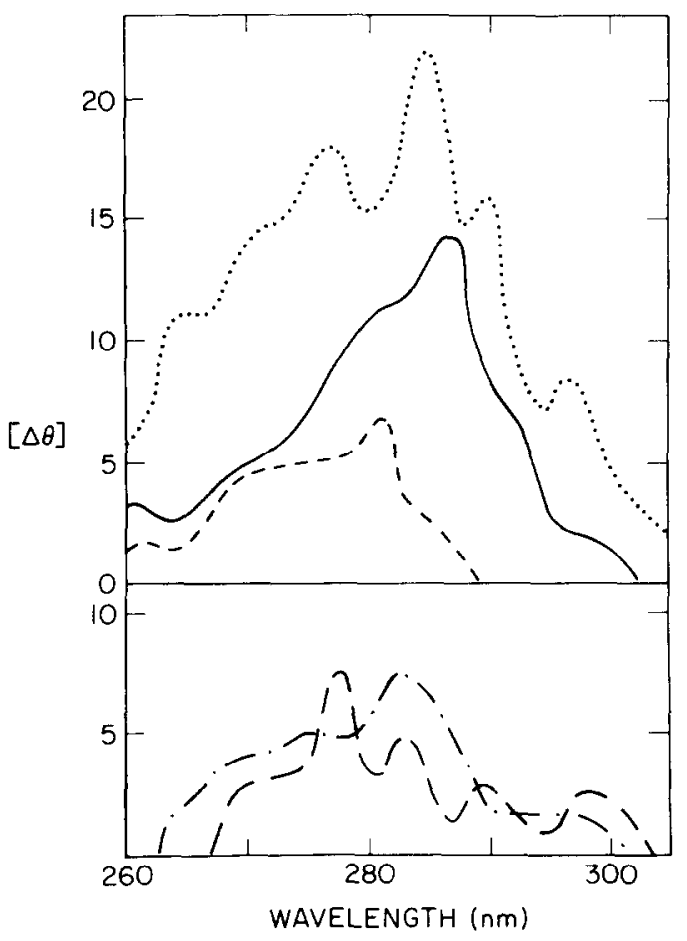

Fig. 2. CD difference spectra of the proteins of Fig. 1. calculated as $\theta$ (protein plus phosphocholine) $-\theta$ (native

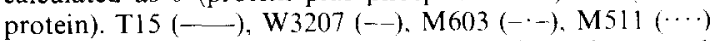
and M167 (--). The errors are estimated as \pm 1 degree $\mathrm{cm}^{2} / \mathrm{dmole}$. 


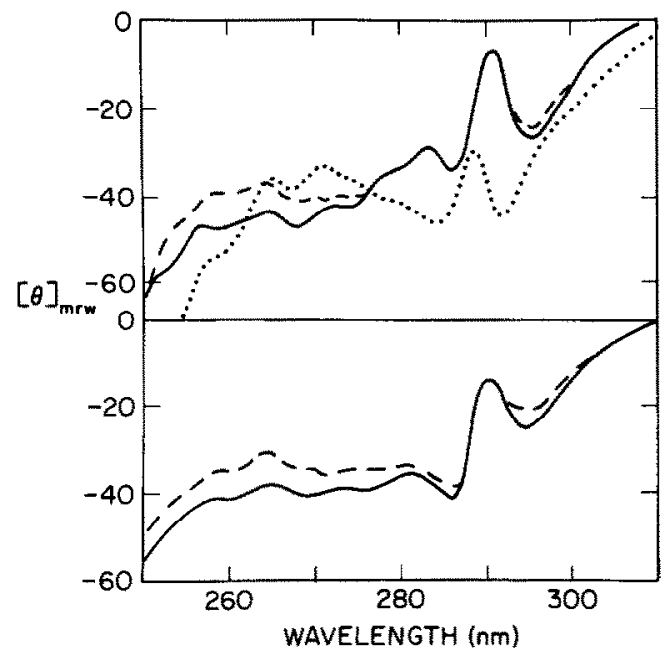

Fig. 3. CD spectra of dextran-specific myeloma proteins. Upper diagram, M104E (-), M104E plus nigerose (--)

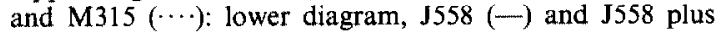
nigerose (---).

constants for phosphocholine of M511 is 10 times lower than that of M167 (Metzger et al., 1971).

\section{Effect of isotype differences on the $C D$ spectra}

The phosphocholine-specific myeloma proteins above are all IgAs, whereas the hybridoma proteins specific for the same determinant are often IgMs. To allow comparison of the hybridoma proteins to the myeloma proteins, the effect of the class change on the CD spectrum was investigated. An almost ideal pair of myeloma proteins for this purpose are the dextran-specific proteins M104E, an IgM (Leon et al., 1970), and J558, an IgA (Lundblad et al., 1972). These two proteins differ only in two residues in their $F d$ regions and have identical $L$-chains. The sequence at residues $96 \mathrm{H}$ and $97 \mathrm{H}$, the $\mathrm{D}-\mathrm{J}_{\mathrm{H}}$ junction, is Tyr $\Lambda$ sp in M $104 E$ and $\Lambda$ rg Tyr in J558 (Schilling $e t$ al., 1980). The CD spectra of the two proteins (Fig. 3) are very similar in form, only a minor difference near $280 \mathrm{~nm}$ being apparent. Hence the class change from IgA to IgM has little effect when comparing CD spectra of mouse immunoglobulins.

When the specific hapten, nigerose, was added in site-saturating amounts, the CD spectra of M104E and $\mathrm{J} 558$ underwent very similar changes (Fig. 3); the slight difference around $280 \mathrm{~nm}$ is within experimental error. These small changes in the tyrosine region occurring with M104E and J558 on ligand binding contrast with the large changes, particularly in the tryptopian region, seen with M315 when this IgA binds dinitrophenyl haptens (Rockey and Freed, 1976). The CD spectrum of M315 resembles those of M104E and J558 (Fig. 3) possibly due to the homology of its $\lambda_{2}$ light chain to the $\hat{\lambda}_{1}$ of M104E and J558 (Dugan et al., 1973).

\section{$C D$ spectra of hybridoma proteins}

Two hybridoma proteins from each of the three families of phosphocholine-binding proteins were

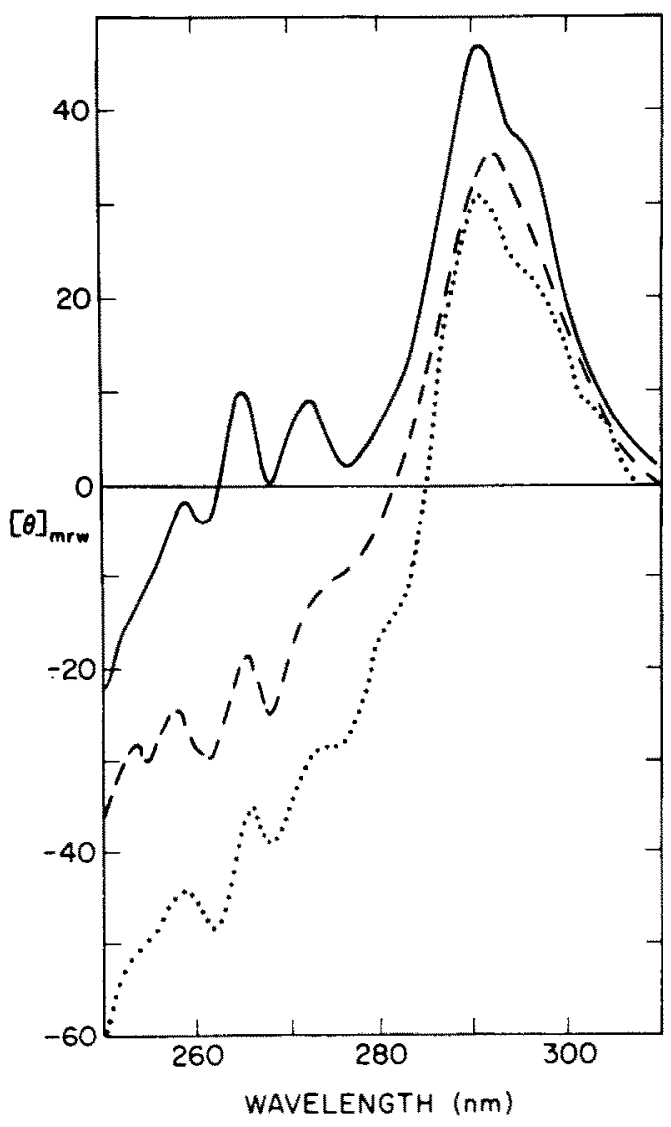

Fig. 4. CD spectra of hybridoma proteins of the T15 family. Protein 59.6C5.1 (-), 103.1C9.1 ( - ) and the myeloma protein $\mathrm{T} 15(\cdots)$.

studied, four of the six being IgMs. It is worth noting that relatively little protein, approx. $1 \mathrm{mg}$, is needed to obtain a CD spectrum and to examine the effect of one hapten. The spectra are presented in Figs 4-6. Correct assignment of all these proteins to their respective families on the basis of the shape of their $\mathrm{CD}$ spectra would not have been possible. Proteins 59.6C5.1 (an IgG3) and 103.1C9.1 (an IgG2) might have been correctly assigned to the T15 family (Fig. 4) and $100.6 \mathrm{G} 2.2$ and $100.6 \mathrm{~F} 9.1$ to the M603 family (Fig. 5), but the two proteins from the M167 family, 101.3C2.2 and 101.6G6 (Fig. 6), show a greater resemblance to T15 and M603 respectively. $\mathrm{CD}$ spectra do not therefore offer an accurate way of classifying hybridoma proteins into families.

Ligand effects on the $\mathrm{CD}$ spectra were examined for most of the proteins. The 59.6C5.1 protein behaved similarly to T15 and $100.6 \mathrm{G} 2.2$ and $100.6 \mathrm{~F} 9.1$ to M603, as expected. The behavior of the M167-type proteins was markedly different (Fig. 6). 101.3C2.2 gave a difference spectrum resembling that of M511 in shape but of only about half the $\Delta \theta$ magnitude. The $101.6 \mathrm{G} 6$ protein gave an extremely large change described below.

Unique properties of the hybridoma protein $101.6 G 6$ In its native $\mathrm{CD}$ spectrum (Fig. 6) 101.6G6 re- 


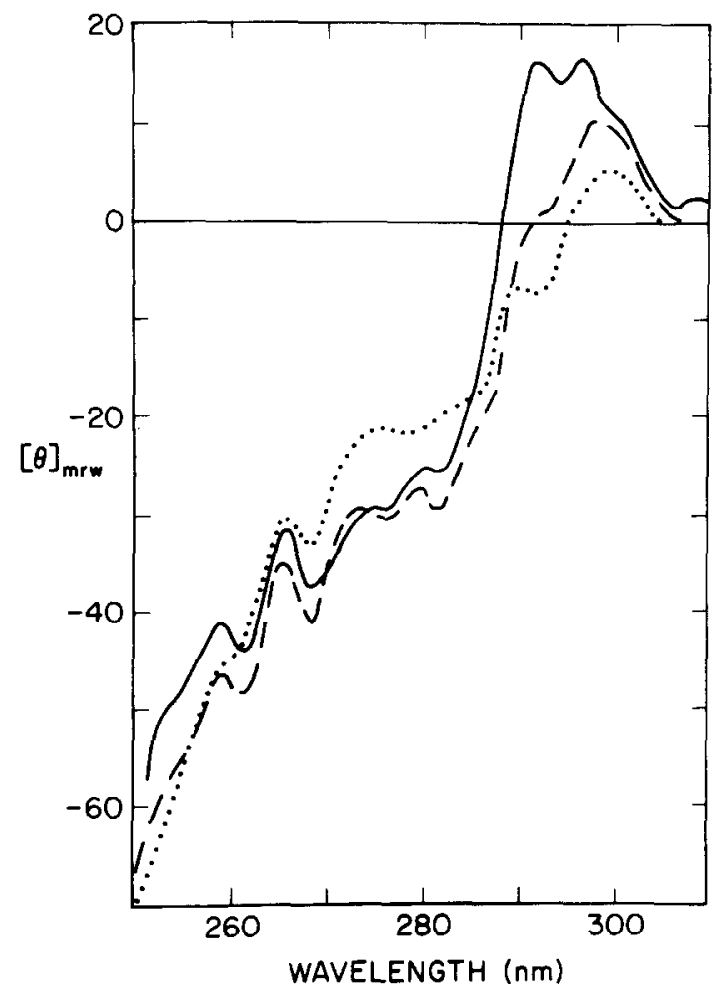

Fig. 5. CD spectra of hybridoma proteins of the M603

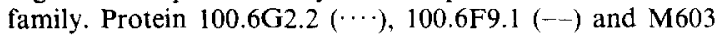
$(-)$

sembles M603 more than M167. When phosphocholine is bound, a very large change occurs in the $C D$ spectrum, while binding of acetylcholine causes a qualitatively similar change but of only half the $\Delta \theta$ magnitude. This contrasts with the behavior of T15 where the two haptens caused very similar spectral changes (Morris et al., 1974).

In these experiments, phosphocholine was added as the calcium salt, and calcium binding can cause changes in spectroscopic properties of immunoglobulins (Bhattacharjee and Glaudemans, 1983). Addition of calcium ion to the native $101.6 \mathrm{G} 6 \mathrm{did}$ not affect the $C D$ spectrum and, when phosphocholine was added as the sodium salt to $101.6 \mathrm{G} 6$ in $20 \mathrm{mM}$ EDTA or $5 \mathrm{mMCaCl}$, the difference CD spectra and spectrophotometric titration curves (sec bclow) were within experimental error. Hence calcium ions are not responsible for any part of the spectral differences and do not play a role in ligand binding.

The magnitude of the CD changes allowed the association constants for phosphocholine and acetylcholine to be measured by $C D$ spectrophotometric titrations. Previous studies (Clarke et al., 1983) using fluorescence spectroscopy had not given such data, as no changes occurred in the fluorescence properties of 101.6G6 when phosphocholine was bound. This is in surprising contrast to the effects seen in the CD. The titration data (Fig. 7) were recorded at $290 \mathrm{~nm}$ : similar results were obtained measuring at $265 \mathrm{~nm}$. Scatchard plots of the titration data (Fig. 8) were obtained using the equation $r / c=n K-r K$, where $r$ is the number of moles of ligand bound per mole of combining site, assuming a mol. wt of 75,000 per site, $c$ is the concentration of free ligand and $K$ is the association constant. For phosphocholine, $K$ was $1.1 \pm 0.1 \times 10^{5} M^{-1}$ and for acetylcholine $5.8 \times$ $10^{2} M^{1}$. The ratio of the two $K$-values lies between the ratios for M167 and T15 (or M603) obtained in inhibition experiments (Leon and Young, 1971).

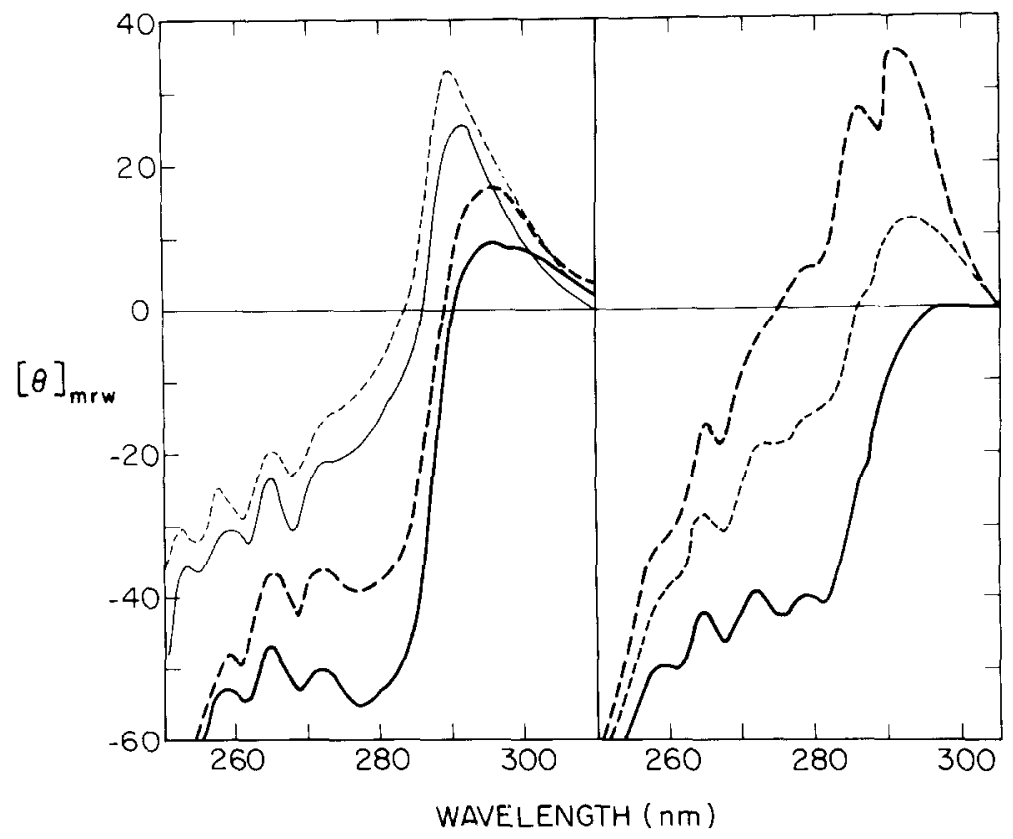

Fig. 6. CD spectra of hybridoma proteins of the M511 family. Left panel, protein 101.3C2.2 (- - ) and with phosphocholine added (--); M511 (-) and with phosphocholine added (--). Right panel, protein 101.6G6 (- $)$ and with acetylcholine added (--) or phosphocholine added (--). Each ligand was added in saturating amounts. 


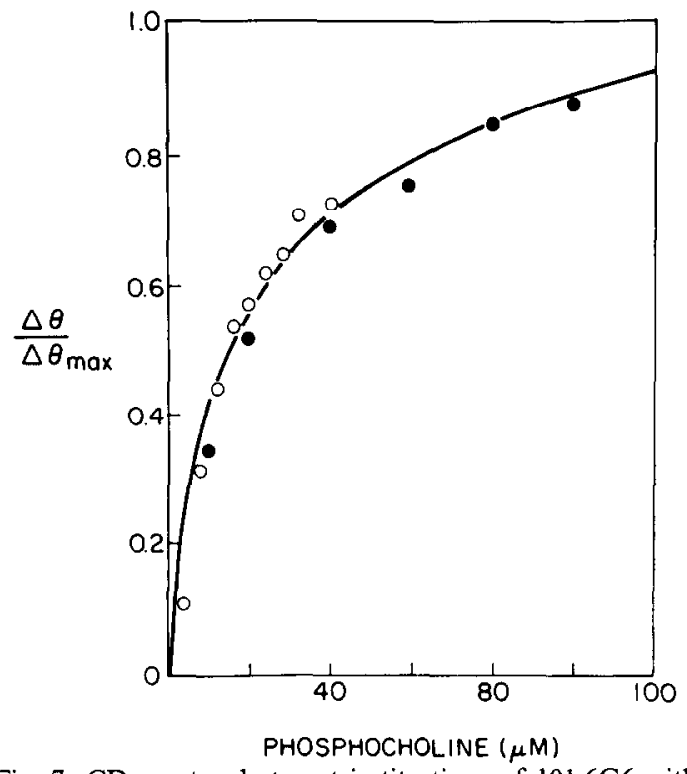

Fig. 7. CD spectrophotometric titrations of $101.6 \mathrm{G} 6$ with the sodium salt of phosphocholine in: (a) $5 \mathrm{mM} \mathrm{CaCl}$, $0.15 \mathrm{M} \mathrm{NaCl}, 0.02 \mathrm{M}$ imidazole buffer, $\mathrm{pH} 7.2(\mathrm{O})$; and (b) $0.15 M \mathrm{NaCl}, 20 \mathrm{~m} M$ EDTA, pH 7.2 (O).

\section{DISCUSSION}

CD differences between related proteins in the aromatic region of their spectra can arise in two ways. Firstly, there may be some direct sequence differences involving tyrosine and tryptophan residues being replaced by other residues. Secondly, sequence differences of residues nearby tyrosine and tryptophan residues in the three-dimensional structure of the protein may affect their conformation or influence their electronic properties. To analyse the latter, extensive model building and interpretation of ligand binding would be necessary. Studies of this type have been undertaken for M315 (Padlan et al., 1977), J539 (Feldman et al., 1981), M167 (Coutre et al., 1981) and M104E (Hovis, 1982). Comparison of the direct changes in sequence involving aromatic residues is more readily undertaken, but is much less complete.

Amino-acid sequence data for the five phosphocholine-specific myeloma proteins (Kabat et al., 1983) and two of the hybridoma proteins (Clarke et al., 1983) are summarized in Table 1 for those CDRs that show differences involving tyrosine or

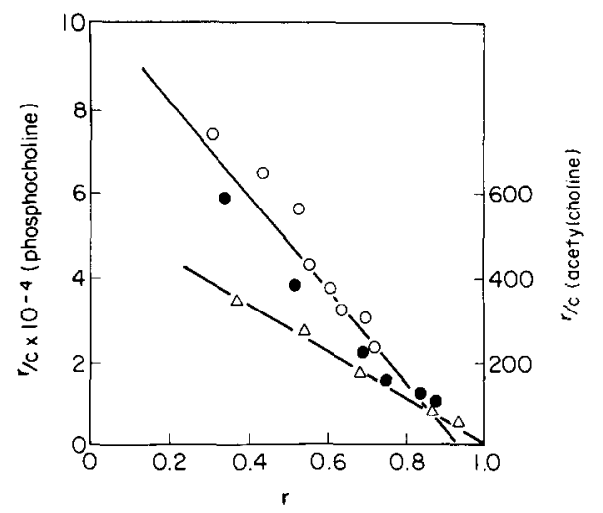

Fig. 8. Scatchard plot of the data from the CD spectrophotometric titrations of $101.6 \mathrm{G} 6$. Phosphocholine titrations in $\mathrm{CaCl}_{2}(\mathrm{O})$ and EDTA $(O)$ from Fig. 7, and an acetylcholine titration $(\triangle)$.

tryptophan residues. M603 is taken as the prototype since its structure is being determined by X-ray crystallography (Padlan et al., 1976). The aromatic sequence differences occur mainly in the CDR 1 of the L-chain and the CDR3 of the H-chain. The role of the CDR3 in antibodies has not been absolutely established. It has been suggested that it has a structural rather than antigen-binding function (Potter, 1983). It is probable that the variation in the native $C D$ spectra among the proteins arises mainly from the differences in their CDR3 sequences.

The variation in the $C D$ effects upon phosphocholine binding (Fig. 2) shows that the aromatic residues in the binding sites are not equivalent in properties. Either the tyrosine and tryptophan residues common to the five take up different conformations in each case, in either native or ligandbound states or both, or additional aromatic residues are affected by binding. The source of such additional rcsidues would predominantly be CDR3, which would imply that antigen binding affects this region.

The pair of dextran-specific myeloma proteins $\mathrm{M} 104 \mathrm{E}$ and $\mathrm{J} 558$ differ also at the $\mathrm{D}-\mathrm{J}_{\mathrm{H}}$ junction, with Tyr-Asp in M104E becoming Arg-Tyr in J558, at residues 96 and 97 (Schilling et al., 1980). No significant differences between the two proteins in the effect of binding the hapten nigerose were seen (Fig. 3 ), hence these tyrosines are not different in their CD properties. A recent model for the M104E site and its

Table 1. Sequence data for the CDRs that show differences in tyrosine and tryptophan residues

\begin{tabular}{|c|c|c|c|c|}
\hline \multirow[b]{2}{*}{ Protein } & \multicolumn{3}{|c|}{$\mathrm{H}$-chain CDR $3^{a}$} & \multirow{2}{*}{$\begin{array}{l}\text { L-chain } \\
\text { (compared to M603) }\end{array}$} \\
\hline & $\mathrm{V}_{\mathrm{H}}$ & D & $\mathrm{J}_{\mathrm{H}}$ & \\
\hline M603 & $\mathrm{N}$ & YYGST & WYF & \\
\hline W3207 & $N$ & YYKYDL & WYF & Sequence not available \\
\hline $100.6 \mathrm{F9}$ & $\mathrm{N}$ & YYDGSY & WYF & \\
\hline $\mathrm{T} 15$ & $\mathrm{D}$ & YYGSSY & WYF & $27 \mathrm{C} \mathrm{L} \rightarrow \mathrm{Y} ; 32 \mathrm{~F} \rightarrow \mathrm{Y} ; 55 \mathrm{E} \rightarrow \mathrm{Y} ; 92 \mathrm{H} \rightarrow \mathrm{Y}$ \\
\hline M167 & $\mathrm{D}$ & ADYGDSYF & GYF & $27 \mathrm{D} \mathrm{N} \rightarrow \mathrm{Y} ; 32 \mathrm{~F} \rightarrow \mathrm{Y}$ \\
\hline M511 & $\mathrm{D}$ & GDYGSSY & WYF & $27 \mathrm{D} \mathrm{N} \rightarrow \mathrm{Y} ; 32 \mathrm{~F} \rightarrow \mathrm{Y}$ \\
\hline $101.6 \mathrm{G} 6$ & A & NWDG & $\mathbf{F}$ & $27 \mathrm{D} \mathrm{N} \rightarrow \mathrm{Y} ; 32 \mathrm{~F} \rightarrow \mathrm{Y}^{b}$ \\
\hline
\end{tabular}

${ }^{a} \mathrm{CDRs} 1$ and 2 have no differences in their aromatic residues.

'Sequence known only through CDR1 (Clarke et al., 1983). 
binding of nigerose (Hovis, 1982) includes a hydrogen bond from the hydroxyl of Tyr $96 \mathrm{H}$ to the hapten. Thus differences in the behavior of the two proteins might have been anticipated, but are not evident in these CD experiments.

Additional spectra and sequence data on hybridoma proteins should help with the analysis begun above. The findings with the present group showed that hybridoma proteins of the T15 and M603 families are generally consistent in their CD properties while the M167 family is a rather variable one. This confirms the results obtained by ligand profiling (Andres et al., 1981). The four members of the M167 family studied here all differed in the shape of their native spectra and, more importantly, in the effect of hapten binding on their $\mathrm{CD}$. The latter effects ranged from a small change in the case of M167, a larger one for 101.3C2.2, a still larger one for M511, which gave the greatest change of the group of myeloma proteins, to the very large change occurring with 101.6G6. Hence, the variation in the M167 family seen in the binding of analogs of phosphocholine (Andres et al., 1981) is shown by the CD results to extend to the details of the interaction of the prototypic hapten, phosphocholine, with the combining sites. This family should therefore be particularly valuable for correlating the variation of function with structure, when the necessary sequence data are available and the M167 structural model (Coutre et al., 1981) is refined.

The hybridoma protein 101.6G6 has been classified as a member of the M167 family on the basis of idiotypy and ligand profile (Andres et al., 1981). Sequence work has shown that its L-chain is homologous to that of M167 (Clarke et al., 1983). However, its $\mathrm{H}$-chain is derived from the VII member of the T15 gene family (Clarke et al., 1982) rather than the $V I$ genc used by the other phosphocholine-binding immunoglobulins (Crews et al., 1981). The H-chain of M47A is also derived from the VII gene and formed phosphocholine-binding immunoglobulins when combined in vitro with the $101.6 \mathrm{G} 6$ or M511 L-chains (Pierce et al., 1984). Hence 101.6G6 can be considered as the prototype of a fourth family of phosphocholine-specific immunoglobulins.

The magnitude of the $C D$ spectral changes seen with $101.6 \mathrm{G} 6$ is unusually large for a protein-ligand interaction. The different effects of acetylcholine and phosphocholine binding to $101.6 \mathrm{G} 6$ indicate different interactions around the quaternary ammonium moieties of the two ligands are occurring. This situation is analogous to previous results, obtained by resonance Raman spectroscopy, on the variation in behavior around the nitro groups of various dinitrophenyl ligands when bound to M315 and M460 (Kumar et al., 1978). That an antibody combining site may adopt different conformations around apparently homologous regions of hapten is in accord with current views of the flexible nature of protein active sites in general.
The association constant obtained by CD spectrophotometric titration for $101.6 \mathrm{G} 6$ at $1 \times 10^{5} \mathrm{M}$ । is slightly below that of M167, $1.2 \times 10^{5} M^{-1}$ at pH 8.0, but well above that of M511, $1.6 \times 10^{4} \mathrm{M}^{-1}$ (Metzger et al., 1971). Hence the apparently large conformational change accompanying hapten binding does not reduce the effectiveness of $101.6 \mathrm{G} 6$ as a phosphocholine-binding protein, and evidently immunoglobulins derived from the $V I I$ gene can be as effective as those from the $V I$ gene.

Scveral structural features may contribute to the large $C D$ effects seen with $101.6 \mathrm{G} 6$. The differences between the 101.6G6 and other H-chain CDRs include an interesting difference in CDR1. In 101.6G6 the sequence Tyr-Tyr-Met-Ser occurs instead of the Phe-Tyr-Met-Glu sequence of the other proteins. The latter is characteristic of phosphocholine-binding immunoglobulins (Kabat et al., 1976) and includes residues that contact the hapten (Padlan ct al., 1976). The additional tyrosine, a potential CD chromophore, in the CDR 1 of $101.6 \mathrm{G} 6$ may be important for the protein's spectroscopic behavior. Secondly, the D-seginent of $101.6 \mathrm{G} 6$ is considerably different in sequence and creates a much shorter CDR3 than those of the other proteins (Clarke et al., 1983). It contains no tyrosine residues and one tryptophan, whereas the others have several tyrosines and except M167, one tryptophan. Finally, there may be differences in the overall association of a VII gene H-chain with a VK24 L-chain compared to the $V I-V K 24$ system that necessitate greater site rearrangement upon ligand binding.

Acknowledgements - We thank Drs M. Potter, L. Hood and B. Clevinger for gifts of ascites fluids. This work was supported in part by grant $\mathrm{No}_{0}$. Al 12533 from the National Institutes of Health. NRCC publication No. 24052

\section{REFERENCES}

Andres C. M., Maddalena A., Hudak S., Young N. M. and Claflin J. L. (1981) Antiphosphocholine hybridoma antibodies II. Functional analysis of binding sites within three antibody families. J. exp. Med. 154, 1584-1598.

Bhattacharjee A. P. and Glaudemans C. P. J. (1983) Letter to the Editor. J. Immun. 130, 1012.

Chesebro B. and Metzger H. (1972) Affinity labelling of a phosphorylcholine binding mouse myeloma protein. Biochemistry 11, 766-771.

Claflin J. L., Hudak S. and Maddalena A. (1981) Antiphosphocholine hybridoma antibodies I. Direct evidence for three distinct families of antibodies in the murine response. J. exp. Med. 153, 352-364.

Clarke S. H., Claflin J. L., Potter M. and Rudikoff S. (1983) Polymorphisms in anti-phosphocholine antibodies reflecting evolution of immunoglobulin families. $J$. exp. Med. 157, 98-113.

Clarke S. H., Clanlin J. L. and Rudikoff S. (1982) Polymorphisms in immunoglobulin heavy chains suggesting gene conversion. Proc. natn. Acad. Sci. U.S.A. 79, $3280-3284$

Cohn M., Langman R. and Geckeler W. (1980) Diversity 1980. In Progress in Immunology IV (Edited by Fougereau M. and Dausset J.), pp. 153-201. Academic Press, New York. 
Coutre S. E., Stanford J. M., Hovis J. G., Stevens P. W. and Wu T. T. (1981) Possible three-dimensional backbone folding around the antibody combining sitc of immunoglobulin MOPC 167. J. theor. Biol. 92, 417-434.

Crews S., Griffin J., Huang H., Calame K. and Hood L. (1981) A single $V_{H}$ gene segment encodes the immune response to phosphorylcholine: somatic mutation is correlated with the class of antibody. Cell 25, 59-66.

Dugan E. S., Bradshaw R. A., Simms E. S. and Eisen H. N. (1973) Amino acid sequence of the light chain of a mouse myeloma protein (MOPC 315). Biochemistry 12, $5400-5416$

Feldmann R. J., Pulter M. and Glaudemans C. P. J. (198I) A hypothetical space-filling model of the galactan-binding myeloma immunoglobulin J539. Molec Immun. 18, 683-698.

Gearhart P. J., Johnson N. D., Douglas R. and Hood L. (1981) IgG antibodies to phosphocholine exhibit more diversity than their IgM counterparts. Nature, Lond. 291, $29-34$.

Hiramoto R., Ghanta V. K., McGhee J. P. Schrohenloher R. and Hamlin M. M. (1972) Use of dextran-conjugated columns for the isolation of large quantities of MOPC 104E IgM. Immunochemistry 9, 1251-1253.

Hovis J. G. (1982) Prediction of a three-dimensional structure for the MOPC 104E $\alpha(1,3)$ dextran antibody-antigen complex. Ph.D. thesis, Northwestern University.

Kabat E. A. (1981) Gaps in understanding the mechanism by which antibody specificity and complementarity are generated. In The Immune System (Edited by Steinberg C. M. and Lefkovits I.), Vol. 2, pp. 113-125. Karger, Basel.

Kabat E. A. (1982) Antibody diversity versus antibody complementarity. Pharmac. Rev. 34, 23-37.

Kabat E. A., Wu T. T. and Bilofsky H. (1976) Attempts to locate residues in complementarity-determining regions of antibody combining sites that make contact with antigen. Pror. natn. Acad. Sci. U.S.A. 73, 617-619.

Kabat E. A., Wu T. T., Bilofsky H., Reid-Miller M. and Perry H. (1983) Sequences of Proteins of Immunological Interest. U.S. Department of Health and Human Services.

Kumar K., Phelps D. J., Carey P. R. and Young N. M. (1978) Resonance Raman spectroscopic studies of the hapten features involved in the binding of 2,4-dinitrophenyl haptens by the mouse myeloma pro- teins MOPC 315 and MOPC 460. Biochem. J. $727-$ 735.

Leon M. A. and Young N. M. (1971) Specificity for phosphorylcholine of six murine myeloma proteins reactive with Pneumococcus $\mathrm{C}$ polysaccharide and $\beta$-lipoprotein. Biochemistry 10, 1424-1429.

Leon M. A., Young N. M. and McIntyre K. R. (1970) Immunochemical studies of the reaction between a mouse myeloma macroglobulin and dextrans. Biochemistry 9, 1023-1030.

Lundblad A., Steller R., Kabat E. A., Hirst J. W., Weigert M. G. and Cohn M. (1972) Immunochemical studies on mouse mycloma protcins with spccificity for dextran or for levan. Immunochemistry 9, 535-544.

Metzger H., Chesebro B., Hadler N. M., Lee J. and Otchin N. (1971) Modification of immunoglobulin combining sites. In Progress in Immunology (Edited by Amos B.), pp. 253-267. Academic Press, New York.

Morris D. H., Williams R. E. and Young N. M. (1974) Comparison of three phosphocholine-binding mouse myeloma proteins by circular dichroism. Biochem. biophys. Res. Commun. 61, 1167-1173.

Padlan E. A., Davies D. R., Rudikoff S. and Potter M. (1976) Structural basis for the specificity of phosphocholine-binding immunoglobulins. Immunochemistry 13, 945-949.

Padlan E. A., Davies D. R., Pecht I., Givol D. and Wright C. (1977) Model building studies of antigen binding sites. The hapten-binding site of MOPC 315. Cold Spring Harb. Symp. quant. Biol. 4, 627-637.

Pierce J. W., Hudak S. and Claflin J. L. (1984) The role of a novel VH sequence (VII) in the formation of antiphosphocholine antibodies. Molec Immun. 21, 159-166.

Potter M. (1983) Structural correlates of immunoglobulin diversity. Surv. immun. Res. 2, 27-42.

Rockey J. H. and Frecd R. M. (1976) Circular dichroism of hapten-antibody complexes: characterisation of the combining sites of native and reformed MOPC 315 protein, its isolated subunits and its Fv fragment. Srand. $I$. Immun. 5, 655-666.

Schilling J., Clevinger B., Davie J. M. and Hood L. (1980) Amino acid sequence of homogeneous antibodies to dextran and DNA rearrangements in heavy chain Vregion gene segments. Nature, Lond. 283, 35-40.

Tonegawa S. (1983) Somatic generation of antibody diversity. Nalure, Lond. 302, 575-581. 